\title{
Grupo de Apoio com Pacientes Psiquiátricos Ambulatoriais em Contexto Institucional: Análise do Manejo Terapêutico
}

\author{
Carla Guanaes \\ Marisa Japur ${ }^{12}$ \\ Universidade de São Paulo, Ribeirão Preto
}

\begin{abstract}
Resumo
Objetivou-se neste estudo refletir sobre o emprego das práticas grupais em contexto institucional no tratamento de pacientes psiquiátricos ambulatoriais. Para tanto, buscou-se compreender a natureza de um grupo de apoio em um serviço de saúde mental, através da descrição do manejo terapêutico de seu terapeuta. Observação, registro audio-gravado e transcrição das dezesseis sessões constituíram as principais fontes de dados; consultas aos prontuários dos pacientes e notas de campo favoreceram a contextualização dos resultados. A análise das intervenções do terapeuta $(N=1904)$ foi realizada por procedimentos de análise categorial de conteúdo, derivando em oito categorias descritivas do manejo do grupo. Assim, este estudo favorece um entendimento sobre a natureza de um grupo de apoio, situando alguns de seus limites e possibilidades, e estimula reflexões sobre a prática grupal em contexto institucional no tratamento de pacientes psiquiátricos ambulatoriais.

Palavras-chaves: Grupo de apoio; pacientes psiquiátricos; tratamento ambulatorial; manejo terapêutico.
\end{abstract}

\section{Support Group with Psychiatric Outpatients in Institutional Context: The Group's Handling Analysis}

\begin{abstract}
This study aims an understanding about the group practice in institutional contexts, on psychiatric outpatients treatment. It was objetified to understand the nature of a support group realized on a mental health service, by describing its development through the cordinator's handling. Observation and audio-recorded tapes of the group (16 sessions) constituted the main data sources. Consultations to the patients' reports and field notes favored an understanding about the group context. The group's handling analysis was accomplished by categorical content analysis of the coordinator's interventions ( $N=1904)$, resulting in eight descriptive categories. Thus, this is study favors an understanding about the support group nature, by showing some possibilities and limits of this kind of treatment, and it arouses reflections about the group practice in institutional contexts on the psychiatric outpatients treatment.

Keywords: Support group; psychiatric outpatients; ambulatory care; therapeutic handling.
\end{abstract}

A prática da psicoterapia de grupo tem apresentado um acentuado crescimento em nossa realidade, sobretudo determinada por pressões de ordem econômica e modificações nas concepções e formas de tratamento em saúde mental (Birman \& Costa, 1994; Lancetti, 1993). Embora respondendo também à necessidade de redução dos custos e de aumento do índice de atendimentos em psicoterapia, esta prática tem se expandido e se mostrado uma modalidade de intervenção viável em decorrência de avanços teóricos e técnicos nesse campo (Scheidlinger, 1994). O panorama atual revela uma multiplicidade de intervenções psicoterápicas em grupo nos mais variados contextos e evidencia a crescente aceitação desta prática entre os profissionais e entre os próprios pacientes, sobretudo nas instituições.

\footnotetext{
${ }^{1}$ Endereço para correspondência: Avenida dos Bandeirantes, 3900, Campus da USP, Ribeirão Preto, 14040-901, SP. Fone: (16) 6023735, Fax: (16) 6023793 E-mail:mjapur@ffclrp.usp.br

${ }^{2}$ Apoio financeiro: FAPESP
}

Apesar dessa grande expansão das práticas grupais, existe ainda uma grande confusão conceitual nas definições dos diferentes grupos realizados, sendo que apenas a nomeação de um determinado grupo permite saber pouco sobre sua natureza e modo de funcionamento. Por isso, faz-se fundamental a compreensão da natureza dos grupos estudados, para além de suas denominações, para um entendimento sobre as possibilidades e limites terapêuticos destas várias formas de intervenção (Dies, 1992; Ishara, 1996).

Diferentes autores sugerem a classificação dos grupos segundo alguns critérios específicos, assim buscando diminuir a tendenciosidade em suas definições e melhor delimitar as diferentes práticas de grupo em função de seus objetivos, técnica e alcance terapêutico (Vinogradov \& Yalom, 1992; Zimerman, 1997). Entendemos que essas tentativas de classificação dos grupos podem funcionar como mapeadoras das especificidades dessas diferentes modalidades de intervenção, alertando para aspectos que devem ser considerados no momento da composição de um grupo específico. 
Neste sentido, um dos aspectos que tem sido apontado como relevante pela literatura é a necessidade de cuidados na seleção dos pacientes para os grupos, ou seja, a definição de critérios de inclusão e exclusão, considerando-se por um lado, as características individuais, os diagnósticos ou o funcionamento psicodinâmico dos participantes, e por outro, a própria finalidade do grupo a ser constituído e sua orientação terapêutica (Contel, 1997; Klein, 1996; Rosemberg \& Zimet, 1995; Sanches 2000). Estudos presumem que uma seleção adequada de pacientes reduz o índice de abandono no tratamento, além de contribuir para o desenvolvimento da coesão grupal, fundamental no estabelecimento de comportamentos no grupo favoráveis à mudança (Salvendy, 1996).

Além disso, segundo Vinogradov e Yalom (1992), três características flexíveis dos grupos de terapia - o contexto, seus objetivos e a estrutura de tempo que os organiza também devem ser consideradas na composição de qualquer grupo, pois influenciam diretamente em suas finalidades e na adoção de uma determinada orientação terapêutica.

Especificamente em relação aos grupos de apoio e de curta duração, a literatura aponta alguns aspectos que podem contribuir para seu melhor desenvolvimento, como por exemplo, uma abordagem terapêutica adequada, posturas terapêuticas mais ativas por parte do coordenador, o estabelecimento de focos e objetivos para o tratamento e uma relativa homogeneidade na composição do grupo (Klein, 1996; Mackenzie, 1996; Vinogradov \& Yalom, 1992). Tais características serão especialmente consideradas a seguir, visando a caracterização da especificidade destes grupos.

Segundo sugere Mackenzie (1996), a psicoterapia de grupo de curta duração utiliza muitas técnicas em comum com a psicoterapia de grupo em geral, mas sua singularidade reside no uso intencional do tempo para a aceleração do processo terapêutico. Para este autor, a natureza breve da intervenção conduz a uma organização de grupo diferenciada, em que se busca explorar temas específicos visando a possibilidade de desenvolvimento dos participantes em uma estrutura de tempo limitado.

Tem sido consenso entre diferentes autores que o sucesso de uma terapia de grupo breve reside na postulação de objetivos específicos que possam ser alcançados por seus membros durante o tratamento (Rosemberg \& Zimet, 1995; Klein, 1996). Budman, Simeone, Reilly e Demby (1994) sugerem que, ao invés de se trabalhar com o conceito de cura geralmente presente em tratamentos de longa duração, os grupos de curta duração devem favorecer o oferecimento de apoio, objetivando, entre outros aspectos, o alívio de sintomas, o restabelecimento do equilíbrio psicológico, um maior conforto em suas relações interpessoais e um maior nível de auto-entendimento.

Além da definição cuidadosa de objetivos que sejam articulados às possibilidades oferecidas por uma psicoterapia grupal breve, outros aspectos devem ser considerados, tais como a seleção dos pacientes para o grupo e seu manejo e orientação terapêutica.

Em relação à composição dos grupos de curta duração, uma relativa homogeneidade dos pacientes quanto a diagnósticos clínicos ou situações interpessoais similares tem sido considerada fundamental para o mais rápido estabelecimento da coesão grupal e desenvolvimento do grupo (Klein, 1996; Mackenzie, 1996; Salvendy, 1996).

Além disso, a literatura também tem apontado a importância de que o tratamento nestes grupos seja orientado por um foco. Este aspecto encontra-se geralmente relacionado a uma postura do terapeuta de estímulo à troca de experiências e de questões similares entre os pacientes (Budman e colaboradores, 1994).

De acordo com Mackenzie (1996) num grupo de curta duração o terapeuta deve ser tão ativo quanto necessário para manter a atenção dos membros na temática do grupo e nos objetivos do tratamento. Isto não significa que o terapeuta controla o processo do grupo, mas que busca manter o foco temático e encorajar a participação ativa dos participantes, sendo que grande parte deste trabalho pode ser feita por intervenções de reforço e encorajamento. Geralmente, atitudes diretivas, apoiadoras e ativas por parte do terapeuta, têm sido associadas ao melhor desenvolvimento destes grupos, sendo que o oferecimento de conselhos, tarefas e a utilização de recursos extra-grupais têm sido, muitas vezes, empregados com êxito neste tipo de tratamento (Budman e colaboradores, 1994; Klein, 1996; Mackenzie; 1996).

Comumente, ao abordar os grupos de curta duração, a literatura refere de modo associado os grupos de apoio, pois tanto a homogeneidade entre os participantes como a natureza breve da intervenção aparecem associadas também a esta modalidade de intervenção.

Segundo Schopler e Galinsky (1993), os grupos de apoio têm a função de ajudar as pessoas a lidarem com estresses relacionados a situações de crises comuns, a transições de vida e a fases de dificuldades econômicas. Por isso, geralmente, tais grupos destinam-se ao encontro de indivíduos com problemas semelhantes, dispostos a compartilhar de suas experiências pessoais e a se engajarem no desenvolvimento de um processo coeso e suportivo. 
Para estes autores, espera-se que, nos grupos de apoio, os membros assumam papéis ativos ao compartilharem suas experiências, oferecendo informações, conselhos e estimulando a participação de outros membros. Por outro lado, as intervenções do coordenador tendem a ser variadas, embora seja usual que a discussão no grupo seja não estruturada e que não se centre em interpretações sobre fatores psicológicos. Assim, o terapeuta busca intervir tanto ajudando os membros a confrontarem o que é mal adaptado ou patológico no comportamento um dos outros, como atuando no oferecimento de apoio, na valorização das capacidades positivas entre os pacientes e no fortalecimento de suas defesas.

Entre alguns dos efeitos positivos referidos por participantes de grupos de apoio, encontram-se a melhora em seus recursos sociais, um maior nível de conhecimento sobre as questões discutidas no grupo, a maior capacidade de enfrentamento das situações de vida, a melhora na auto-confiança, a diminuição do medo e da ambigüidade, o alívio emocional e a redução da desesperança (Schopler \& Galinsky, 1993).

Partindo dessa breve contextualização sobre a prática grupal, sua diversidade e algumas particularidades dos grupos de apoio e de curta duração, apresentaremos nosso estudo, definido pela necessidade de uma maior compreensão sobre a natureza de um grupo de apoio, considerando-se, sobretudo, seu contexto institucional e a especificidade da clientela que o constituiu.

Admitimos que a natureza de um grupo é definida, em grande parte, pela maneira como este é concebido por seu terapeuta e pelo modo como se organiza a situação terapêutica - composição do grupo, plano terapêutico e formas de intervenção (manejo terapêutico). Consideramos, além disso, que a inserção institucional do grupo também guarda relações com seu desenvolvimento e processo. Portanto, o entendimento do contexto sócio-histórico em que as práticas grupais se desenvolveram, consolidando-se enquanto importante forma de atendimento nos serviços de saúde mental, também faz-se fundamental na compreensão de aspectos que podem influenciar, positiva ou negativamente, seu potencial terapêutico.

\section{Objetivos}

Objetivou-se, neste estudo, descrever o manejo terapêutico de um grupo de apoio para pacientes psiquiátricos ambulatoriais, através da análise das intervenções do terapeuta no grupo. Visamos refletir sobre o emprego das práticas grupais e, especificamente, sobre a natureza de um grupo de apoio de curta duração, considerando a inserção institucional desta modalidade de intervenção.

\section{Método}

\section{O Grupo Estudado ${ }^{3}$}

O objeto deste estudo constituiu-se de um grupo de apoio oferecido a pacientes psiquiátricos ambulatoriais, em um serviço público de saúde de Ribeirão Preto (SP). Foram selecionados para participação neste grupo específico, pacientes que, após a triagem, aceitaram participar do estudo a partir de seu Consentimento Informado, cujo modelo foi elaborado de acordo com a "Resolução n 196/96 Sobre Pesquisa Envolvendo Seres Humanos" (Brasil: Ministério da Saúde, Conselho Nacional de Saúde, 1996).

O grupo, caracterizado como de breve duração, teve 16 sessões semanais (quatro meses) de uma hora e meia de duração. Foi constituído e coordenado por um médico psiquiatra contratado da instituição, e observado silenciosamente pela pesquisadora (a primeira autora deste artigo). Caracterizou-se como um grupo fechado, iniciado com um número fixo de pacientes e sem admissão de novos participantes ao longo do processo.

Participaram ao longo do grupo dez pacientes (em média, sete pacientes por encontro) sendo oito mulheres e dois homens, com idades entre 29 e 65 anos, a maioria casada e com baixo grau de instrução (primeiro grau incompleto). Apresentavam, predominantemente, história de tratamentos ambulatoriais anteriores e uso de medicação ansiolítica ou antidepressiva. Suas queixas mais freqüentes envolviam queixas somáticas, ansiedade, depressão, dificuldades de relacionamento e/ou de produção, prevalecendo sintomas orgânicos, típicos de ansiedade - como agitação, fobias, aumento ou diminuição do apetite, ou típicos de depressão - como desinteresse, apatia. Quanto aos seus diagnósticos clínicos (CID-10), estes se encontravam predominantemente entre os transtornos neuróticos relacionados ao estresse e transtornos somatoformes (transtorno de ansiedade, transtorno adaptativo, ansiedade generalizada e transtorno dissociativo), e entre os transtornos de humor (distimia e transtorno depressivo recorrente). Apenas um paciente apresentava diagnóstico de transtorno de personalidade e de comportamentos em adultos (transtorno de personalidade borderline) (World Health Organization, 1993).

Assim, o grupo foi composto incluindo pacientes com queixas relativamente similares referentes, sobretudo, a dificuldades atuais de relacionamento e de produção,

\footnotetext{
${ }^{3}$ Este estudo foi realizado após seu projeto ter sido aprovado pela Comissão de Ética Médica da instituição em questão.
} 
indicativas da vivência de uma situação de crise, em uma história de vida marcada por dificuldades de adaptação psicossocial - conforme também sugerido por seus diagnósticos clínicos. Foram excluídos do grupo pacientes com quadros orgânicos, dificuldades de fala, déficits intelectuais e /ou em surto psicótico no momento do encaminhamento.

\section{Procedimentos de Coleta e Análise dos Dados Observação e Registro do Grupo}

O registro do grupo foi realizado através da gravação em audio de todas as sessões, bem como através dos registros de observação, realizados pela pesquisadora (autora) durante os encontros. As fitas foram transcritas na íntegra, acrescidas de informações sobre comportamentos e estados afetivos percebidos durante a observação do grupo.

Considerando-se o objetivo de analisar o manejo terapêutico do grupo, realizou-se, com base em procedimentos de análise categorial de conteúdo (Bardin, 1988), uma classificação das intervenções do terapeuta ao longo dos encontros. Essa análise permitiu uma descrição das diferentes formas de intervenção do terapeuta, a partir de seus elementos comuns, em um sistema de categorias que possibilita um entendimento sobre a natureza do grupo e da forma como foi conduzido em seu processo.

Esse sistema foi elaborado a posteriori, a partir da leitura exaustiva dos dados, buscando significar as intervenções do terapeuta no processo interativo do grupo. Após definidas as categorias, todas as intervenções do terapeuta foram tomadas em seu contexto de interação e classificadas pela autora. Para a análise da fidedignidade dessa classificação, selecionou-se $10 \%$ de todas essas intervenções, de modo a constituir uma amostra casual simples. A classificação independente dessas intervenções no sistema de categorias criado foi realizada por um juiz (a co-autora deste artigo), e a partir disto, procedeu-se o cálculo de acordo entre as classificações, obtendo-se um índice de $88 \%$ de acordo.

\section{Fontes Complementares}

Consideramos como fontes adicionais: 1) consultas regulares aos prontuários dos pacientes; 2) síntese descritiva das sessões do grupo - realizada com base no registro das sessões, a partir da definição de alguns eixos centrais de análise: os participantes presentes em cada sessão do grupo; os assuntos referidos; os temas discutidos; o padrão predominante de interação entre os membros; a tonalidade afetiva presente no grupo e a postura do terapeuta; e 3) notas de diário de campo - com registros sistemáticos sobre o funcionamento da instituição e, mais especificamente, do serviço de saúde mental.

Estas fontes complementares possibilitaram uma análise das sessões e da composição do grupo, bem como um entendimento sobre o contexto institucional em que essa prática psicoterápica se insere.

\section{Resultados}

\section{O Manejo Terapêutico do Grupo}

Apresentamos a definição das categorias resultantes da análise de conteúdo da participação verbal do terapeuta ao longo das sessões do grupo $(N=1904)$, seguida de um exemplo ilustrativo de intervenção em cada uma dessas categorias ${ }^{4}$.

1- Reiteração (Re): Intervenção geralmente breve que consiste ou em resumir a comunicação do paciente ou em assinalar um elemento relevante desta, ou simplesmente em reproduzir as últimas palavras de modo a facilitar a continuação. Pode incluir ainda pequenos questionamentos que visam obter mais informações sobre algum assunto já referido pelo paciente em seu relato. Assim, a reiteração parece ter a função de sustentação da fala do paciente ou grupo.

Ex: Marli: (conta de uma situação em que foi a uma Igreja, no centro da cidade, e cain ao sair desta, perdendo os sentidos) (...) aí eu não sei se eu bati a cabeça..

Terapeuta: A senhora entrou na Igreja porque já estava sentindo mal?

Marli: Desci do ônibus porque já estava passando mal, parece que eu quis vomitá.

Terapeuta: já no ônibus?

Marli: É, no ônibus. Aí eu desci ali na catedral (...). (3a sessão)

2-) Investigação (In): Intervenção que tem como objetivo obter informações suplementares ou provocar mais discussão de um tópico, mostrando ao grupo ou ao paciente que ele pode/ deve desenvolver melhor aquele aspecto. Assim, a intervenção investigativa parece ter a função de ampliar o foco da discussão, possibilitando a reflexão sobre o assunto em pauta ou a universalização no grupo de um assunto tratado por um paciente individualmente.

Ex: Marta: (Fala de seu relacionamento problemático com a mãe, e comenta que acredita que a mãe é doente mental). Às vezes ela fala pra mim: "vocêe é uma doente", e eu falo pra ela: "eu sou, por isso eu me trato". Agora ela não se trata, né?

Terapeuta: Você se acha uma pessoa doente?

Marta: Muito doente. Na alma, entendeu? Eu me acho mais doente do que milhares de pessoas. ( $2^{a}$ sessão)

${ }^{4}$ Os nomes dos pacientes são fictícios a fim de resguardar suas identidades 
3- Elucidação (El): Intervenção que atribui significado ou sentido à comunicação do paciente ou grupo, mostrando algo que não foi percebido por ele e possibilitando a ampliação da percepção sobre si mesmo ou sobre o assunto tratado.

Ex: Roberta: (comenta que perdeu a atração sexual pelo marido, não sentindo prazer com ele; gostaria de reverter esta situaçao) (...) que nem eu tô procurando, aqui. Tô indo pra Igreja, pedindo pra Deus pra voltar o amor que eu tinha antes, que eu não posso continuar assim, que eu nem posso separar dele e arrumar outro por causa das crianças, né? (...) Ah, eu tenho esta esperança ainda (de voltar a sentir o que en sentia antes).

Terapeuta: E você acha que isto depende de coisas que estão fora de você? Igreja, Deus (...) Você vai buscar ajuda, mas você vai buscar isto fora. Como a D. Marli está falando: o amor a Deus e ao marido não.

Roberta: Às vezes volta assim com o tempo, até acabar o tratamento, né? $\quad\left(13^{a}\right.$ sessão)

4-) Confrontação (Co): Intervenção que introduz um elemento de realidade que parece não considerado na fala e/ou atitude do paciente ou do grupo.

Ex: João: Já que ninguém fala, eu vou falar alguma coisa agora. É... sobre a falta de paciência para lidar com o paciente. Minha esposa no caso. Ai, mas tem hora que ela chega a irritar! (...) (Segue relatando situaçōes em que fica perdido, sem saber se as açōes da esposa são intencionais ou se são conseqüência de sua doença).

Terapenta: Eu achei interessante é que você falou no começo, né, "ter paciência de lidar com o paciente". Como se ela fosse sua paciente.

João: Não, minha não. (...)

Terapeuta: Você percebeu?

João: Ah, tá. Não épaciente. Eu sou o quê? Um guardião só... (8a sessão).

5- Enquadre (En): Intervenção relativa ao enquadre, à tarefa grupal e às regras de funcionamento do grupo. Inclui referências ao horário, à modalidade de participação, às possibilidades e limites do grupo, às faltas, às consultas individuais na psiquiatria e ao encerramento do grupo. Além disso, inclui a apresentação de si e do grupo, bem como o estímulo à participação verbal.

Ex: João: (Refere sua preocupaşão com o número de faltas que já teve no grupo). Aliás, a minha preocupaşão, que eu já até perguntei agora bá pouco pra (obervadora), é se eu já deu três faltas sem falar nada. (...)

Terapenta: Em seguida?

João: Não, em seguida não, mas...

Terapeuta: Não pode dar em seguida, em seguida complica. Três faltas seguidas sem avisar. (olba para Roberta) Tem gente aqui que deu três faltas seguidas. (11 a sessão)

6-) Avaliação (Av): Intervenção que geralmente expressa uma opinião do terapeuta sobre o paciente ou grupo, podendo conter também sugestões e conselhos quanto à conduta a ser tomada. Geralmente utilizada para avaliação do desempenho e da participação do paciente durante a sessão ou do grupo como um todo.

Ex: Terapeuta: (ao término do grupo) (...) Vejam vocês, que por ser a primeira vez, este grupo até que foi bastante dinâmico, né, bastante produtivo, quase todo mundo, com raras exceções, fe z alguma colocação

(...) (1' sessão)

7-) Orientação (Or): Intervenção que oferece uma informação objetiva sobre algum assunto / tema tratado no grupo, assim clarificando algo que o paciente ou grupo desconhece.

Ex: (Marta refere os diagnósticos que teria recebido durante seus tratamentos anteriores)

Terapeuta: A senbora quer saber o que que é esquizofrenia on o que que ela tem?

Marli: Não, esta doença.

Terapeuta: É uma doensa da mente. Esquizofrenia é uma doença da mente. A senhora quer saber o que é esquizofrenia? É uma doença que ataca a cabeça das pessoas.

Marli: A pessoa vai pensando, pensando e ataca a cabeça?

Terapeuta: Não é pensando... É que ataca o pensamento. (2a sessão)

8-) Fala Interrompida (FI): Tentativa de intervenção não concluída, por interrupção do paciente ou grupo durante a fala do terapeuta.

Ex: Marta: Não, eu não estou procurando (serviço) não, porque en fiquei desestimulada para trabalhar, por isso en estou desempregada este tempo todo. Fiquei desestimulada pra trabalhar, pra viver, pra tudo, por isto que eu tô desempregada este tempo todo.

Terapeuta: como é que você imagina...

Rosilene: (falando ao mesmo tempo que o terapeuta) Eu não entendi o que ela quis dizer com desestimulada... (2a sessão)

Apresentamos, na Figura 1, a distribuição percentual das intervenções do terapeuta no grupo, considerandose o conjunto das sessões, uma vez que a ordem de freqüência dessas categorias em cada sessão separadamente não apresentou variação. Em seguida, apresentamos esta distribuição considerando-se, separadamente, as intervenções que foram dirigidas aos pacientes individualmente ou ao grupo como um todo (Figura 2).

Conforme podemos observar na Figura 1, o grupo foi coordenado de forma a permitir a livre expressão dos pacientes (reiteração $=48 \%$ ), também favorecendo um espaço para maior reflexão sobre suas problemáticas, a partir de questões de investigação $(16 \%)$ e da postura elucidativa $(13 \%)$ e confrontadora $(11 \%)$ do terapeuta em alguns momentos. Intervenções mais diretivas e objetivas, como de enquadre (7\%), "avaliação" ( $2 \%)$ e "orientação" (1\%), embora típicas em grupos de apoio, foram quase inexistentes. Na Figura 2, por sua vez, podemos observar que a maioria das intervenções do 


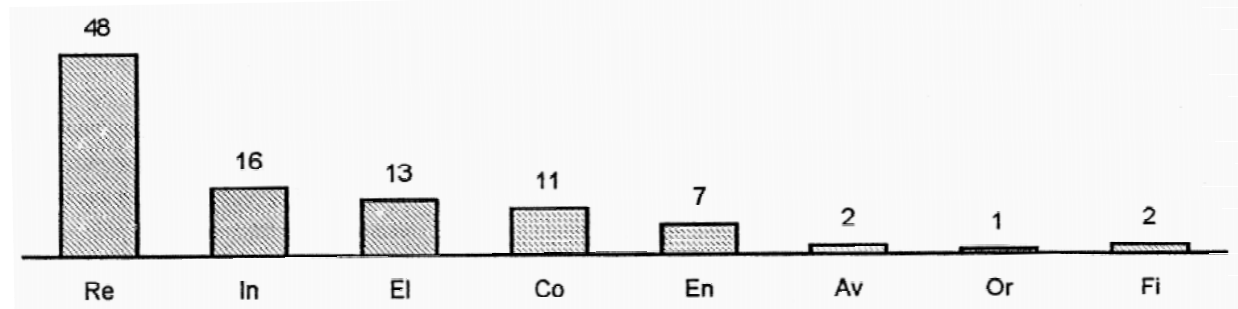

Figura 1. Distribuição percentual das intervenções do terapeuta no conjunto das sessões do grupo $(N=1904)$ pelas categorias de intervenção

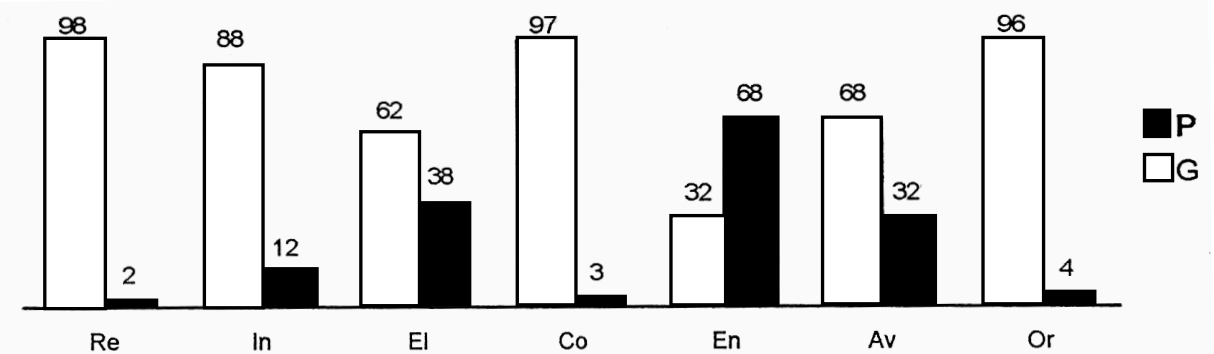

Figura 2. Distribuição percentual das intervenções do terapeuta ( $N=1904)$ dirigidas ao paciente $(\mathrm{P})$ ou ao grupo $(\mathrm{G})$ por categorias de intervenção, no conjunto das sessões do grupo

terapeuta foi dirigida aos pacientes de forma individual, e não ao grupo como um todo.

\section{Discussão}

A análise das intervenções do terapeuta indicou que o grupo foi coordenado de modo a permitir a livre expressão dos pacientes durante as sessões. Predominaram intervenções que reiteravam a fala individual dos pacientes, assim sustentando as longas narrativas e a utilização do espaço do grupo para a exposição pessoal. Intervenções de orientação e informação foram pouco utilizadas e, ao contrário, intervenções de investigação, elucidação e confronto, dirigidas aos pacientes individualmente, apareceram com certa regularidade. Assim, verificamos que o manejo do grupo deu-se por um modelo diferente daquele que é referido pela literatura em relação aos grupos de apoio. A ausência de um maior direcionamento e foco, e a presença de intervenções investigativas, elucidativas e de confronto são sugestivas de processos terapêuticos de maior duração, onde se almeja maior compreensão do conflito em seus aspectos intrapsíquicos.

Verificando o desenvolvimento do grupo a partir da observação e descrição de suas sessões, podemos traçar alguns paralelos entre o modo como os pacientes se posicionaram ao longo do processo e as formas de manejo do terapeuta. Os assuntos discutidos referiamse, em sua maioria, a relatos de experiências e de dificuldades em seus relacionamentos sócio-afetivos, sendo a temática central a compreensão da origem da doença ou das relações entre suas dificuldades e a presença dos sintomas. O modo de funcionamento do grupo e o padrão de interação entre seus membros sugerem que os pacientes concebem o grupo como um espaço de queixa e desabafo, onde cada um teria o seu dia para falar-o que determinava uma postura silente dos demais ou a participação através de sugestões e conselhos. Assim, criavam a possibilidade de expor suas experiências, favorecendo uma atmosfera de respeito à participação do outro e de oferecimento de apoio e orientação entre eles.

Pensando, então, nas possibilidades terapêuticas do grupo a partir da compreensão de seu manejo, concluímos que este se distingue tanto dos grupos de apoio - definidos pela literatura sobretudo pela postura mais diretiva do terapeuta, com oferecimento de orientações, conselhos e apoio, visando alívio sintomático e re-estabelecimento do equilíbrio psicológico anterior; como dos grupos de longa duração - definidos pela postura menos ativa do terapeuta e pela presença marcante de intervenções elucidativas, que facilitem o 
insight, o maior conhecimento intrapsíquico e mudanças de características de personalidade. Ao contrário, sua natureza pode ser compreendida pelos limites de seu contexto, considerando que não podemos pensar esta prática deslocada de sua inserção institucional e da influência de aspectos sócio-históricos relacionados ao desenvolvimento das práticas psicoterápicas em grupo enquanto modalidade de atendimento em saúde mental.

Segundo Lancetti (1993), especificamente no contexto brasileiro, a psicoterapia de grupo teve seu crescimento impulsionado pelas mudanças nas concepções e formas de atendimento em saúde mental, originadas a partir dos movimentos de reforma psiquiátrica que visavam a reintegração social dos pacientes. A redução do número de internações em hospitais psiquiátricos e a conseqüente criação de políticas orientando novas formas de atendimento para esta população, como por exemplo, a expansão dos hospitais-dia e os atendimentos ambulatoriais nos centros de saúde, vieram a transformar $\mathrm{o}$ atendimento em grupo no principal recurso terapêutico nestes contextos.

Além disso, outro aspecto que influenciou o maior emprego dos grupos foi, e continua sendo, a busca de uma maior produtividade do terapeuta no atendimento da demanda e de vantagens de custo em comparação com as demais formas de terapia, o que vai de encontro às exigências de produtividade dos ambulatórios (Bezerra Junior, 1992). Estas pressões sócio-econômicas fazemse ainda mais marcantes em relação aos grupos de apoio e de curta duração, sendo crescente a exigência por este tipo de intervenção.

Segundo Bezerra Junior (1992), o fato de se justificar o emprego das psicoterapias breves apenas em função de suas vantagens de custo e do aumento na demanda de pacientes que buscam tratamento, "pode conduzir a uma posição eticamente insustentável, qual seja a de subordinar estratégias terapêuticas a injunções burocráticas financeiras" (p.160). A duração de um tratamento deve variar em função das necessidades do paciente, o que define um plano terapêutico específico considerando, entre outros aspectos, suas características pessoais, seu quadro clínico e a gravidade de sua doença.

Outro aspecto apontado por este autor refere-se à usual afirmação de que as psicoterapias breves têm alcance terapêutico restrito, promovendo apenas alívio sintomático e rearranjo superficial do funcionamento psíquico do paciente. À psicanálise, ficaria atribuída a cura definitiva, criando uma suposta hierarquia entre as psicoterapias e uma falsa compreensão das demais modalidades de atendimento. Do mesmo modo, o emprego de grupos no tratamento em saúde mental não deve se justificar apenas em função de vantagens econômicas, mas pela possibilidade de que estes constituam "um modelo de atenção que melhor possa responder às particularidades e idiossincrasias da clientela dos ambulatórios" (Bezerra Junior, 1992, p.162).

Um dos aspectos centrais na opção pelas formas de intervenção em grupo é a existência de condições nos serviços de Saúde Mental para uma adequada avaliação e encaminhamento dos pacientes. Estudos demonstram que as psicoterapias de grupo apresentam resultados comparáveis ou melhores que outras modalidades de atendimento psicoterápico, desde que se disponha de uma seleção criteriosa de seus integrantes (Budman e colaboradores, 1994; Contel, 1997; Salvendy, 1996). Especificamente em relação à psicoterapia de apoio em grupos de tempo limitado, pesquisas também apontam para a importância de determinação de metas terapêuticas e de focos para o tratamento, o que deve ser necessariamente trabalhado em conjunto com o paciente antes do início do grupo propriamente dito (Budman e colaboradores, 1994; Klein, 1996; Mackenzie, 1996).

Percebe-se, portanto, a necessidade de que as propostas grupais de intervenção em saúde mental considerem as especificidades de seu contexto e da clientela atendida, de modo a manter a qualidade dos atendimentos e suas finalidades terapêuticas. A reflexão crítica sobre estas questões alerta para os riscos de que os serviços psiquiátricos ambulatoriais, pressionados pela necessidade de atendimento da demanda, desviem-se de sua proposta terapêutica de assistência em saúde mental, prolongando demasiadamente o tratamento dos pacientes.

Um dos aspectos sugestivos desta possibilidade é que, muitas vezes, os atendimentos de curta duração executamse como de longa duração, e ao término de um grupo breve, o paciente não obtém alta e é inserido num outro grupo, dando início a um novo processo psicoterápico. Isto sugere que pressões sócio-econômicas têm influenciado na constituição dos grupos nessas instituições, de modo que a necessidade de atender em psicoterapia um maior número de pacientes, parece determinar a adoção dos atendimentos de curta duração, sem que haja, em paralelo, uma modificação nos objetivos e na forma destas intervenções. Assim, o tempo de duração do grupo é reduzido, mas não se alteram seus objetivos, que continuam semelhantes aos dos grupos de longa duração em moldes tradicionais (Budman e colaboradores, 1994; Salvendy, 1996). Em nosso estudo, isto é percebido a partir dos registros de prontuário, que referem que a maioria dos pacientes já havia recebido atendimentos 
psiquiátricos anteriores, e cerca da metade deles participado de experiências de psicoterapia de grupo.

Outro aspecto a ser considerado é que, em conseqüência da diminuição das internações e da criação de modelos de assistência alternativos aos hospitais, fruto das propostas de desinstitucionalização, a clientela dos ambulatórios mudou consideravelmente. Hoje recebem atendimentos ambulatoriais também pacientes com maior comprometimento, o que aponta para a necessidade de que haja, nesses serviços, condições mínimas para o exercício de uma assistência de qualidade.

Considerando, então, a realidade com que nos deparamos nos sistemas de saúde, faz-se necessário repensar as possibilidades de sobrevivência das práticas grupais neste contexto, para que estas possam ser potencializadas em suas metas terapêuticas, assim desenvolvendo-se de forma a tentar, de fato, reduzir o sofrimento psíquico de seus pacientes.

Estas dificuldades na concretização das propostas terapêuticas nos contextos institucionais parecem refletir também o lugar secundário destinado à saúde mental, comparativamente às demais áreas da saúde. Em nosso estudo, isto foi observado através das dificuldades enfrentadas pelos profissionais, em seu cotidiano, para manter a qualidade da assistência, como por exemplo, na disputa por espaço físico com as demais especialidades médicas, nas dificuldades de reposição na equipe profissional e na carência de recursos para oferecer atendimentos terapêuticos diferenciados, considerando tanto a grande demanda como a heterogeneidade de pacientes que buscam tratamento nestes serviços. Embora situada, esta realidade parece refletir também o cotidiano de outros centros de atendimento que oferecem tratamento ambulatorial em saúde mental e intervenções terapêuticas em grupo.

Tendo considerado alguns aspectos sugestivos de limites na aplicabilidade das práticas grupais e, mais especificamente, do grupo de apoio objeto de nosso estudo, nos propomos a refletir sobre as possibilidades e o potencial terapêutico desta modalidade de intervenção.

A natureza desse grupo de apoio, em grande parte determinada pelas limitações de seu contexto, também caracterizou-se pelas possibilidades criadas a partir das interações entre seus participantes. O setting grupal favoreceu o desenvolvimento de uma sintonia entre a demanda do grupo e a disponibilidade do terapeuta de oferecer um espaço aberto a suas necessidades. Nesse grupo, encontraram-se as muitas diferenças e semelhanças de seus integrantes, que os aproximaram na criação de um espaço de escuta silenciosa, de respeito pela experiência do outro e de apoio mútuo - apoio este que define sua natureza para além das intervenções e formas de manejo de seu terapeuta. Este entrosamento entre as necessidades dos pacientes e a capacidade do terapeuta de oferecer um espaço aberto a esta diversidade é indicativo do valor terapêutico potencial das intervenções em grupo, definido a partir destas trocas interativas e dos relacionamentos interpessoais.

Assim, descrever a natureza desse grupo a partir de definições gerais da literatura não é suficiente para apreender sua especificidade, construída no enfrentamento das dificuldades relativas a sua inserção institucional. Esse contato com a realidade dos serviços públicos de atendimento em saúde mental permite pensar as práticas grupais para além do relacionamento entre pacientes e terapeuta, de modo a incluir também o processo sóciohistórico que impulsionou as transformações da assistência neste campo e favoreceu a emergência do grupo como importante recurso terapêutico.

\section{Referências}

Bardin, L. (1988). Análise de conteúdo. Lisboa: Edições 70.

Bezerra Junior, B. (1992).Considerações sobre terapêuticas ambulatoriais em saúde mental. Em S.A.Tunis \& N.R.Costa (Org), Cidadania e loucura: Politicas de saúde mental no Brasil, (3 ${ }^{\mathrm{a}}$ ed. pp. 133-169). Petrópolis: Vozes.

Birman, J. \& Costa, J. F. (1994). Organização das instituições para uma reforma comunitária. Em P. Amarante (Org), Psiquiatria social e reforma psiquiátrica (pp.41-72). Rio de Janeiro: Fiocruz.

Brasil. Ministério da Saúde (1996). Resolução n 196/96 Sobre pesquisa envolvendo seres bumanos. Brasília: Conselho Nacional de Saúde.

Budman, S. H., Simeone, P. G., Reilly, R. \& Demby, A. (1994). Progress in short-term and time limited group psychotherapy: Evidence and implications. Em A. Fuhriman \& G.M. Burlingame (Orgs.), Handbook of group psychotherapy: An empirical and clinical synthesis (pp.319-339). New York: John Wiley.

Contel, J.O.B. (1997). Psicoterapia com pacientes internados e egressos. Em D.E. Zimerman \& L.C.Osório (Orgs.), Como trabalhamos com grupos (Cap.24, pp. 269-279). Porto Alegre: Artes Médicas.

Dies, R. R. (1992). Models of group psychotherapy: Shifting through confusion. International Journal of Group Psychotherapy, 42, 1-17.

Ishara, S. (1996). Psicoterapia de grupo em Hospital Dia: Proposição de uma metodologia de estudo. Dissertação de Mestrado não publicada. Curso de PósGraduação em Saúde Mental, Faculdade de Medicina de Ribeirão Preto, USP, Ribeirão Preto-SP.

Klein, R. K. (1996). Psicoterapia de grupo a curto prazo. Em H.I.Kaplan \& B.J. Sadock (Orgs.), Compêndio de psicoterapia de grupo (3ª ed., pp. 215-225). Porto Alegre: Artes Médicas.

Lancetti, A. (1993). Clínica grupal com psicóticos: A grupalidade que os especialistas não entendem. Em A. Lancetti (Org), Saúde e loucura: Grupos e coletivos, (nº 4, pp.155-171). São Paulo: Hucitec.

Mackenzie, K. R. (1996). Time limited group psychotherapy. International Journal of Group Psychotherapy, 46, 41-60.

Rosemberg, S. A \& Zimet, C. N. (1995). Brief group treatment and managed mental health care. International Journal of Group Psychotherapy, 45, 367379.

Salvendy, J. T. (1996). Seleção, preparação dos pacientes e organização do grupo. Em H. I. Kaplan \& B. J. Sadock (Orgs.), Compêndio de psicoterapia de grupo ( $3^{\mathrm{a}}$ ed., pp. 63-72). Porto Alegre: Artes Médicas. 
Sanches, R. F. (2000). Grupos de apoio e psicoeducação em transtorno bipolar. Em: J.O.B. Contel (Org.), Anais do VII Ciclo de Estudos em Saúde Mental (pp.192-195). Ribeirão Preto, SP.

Scheidlinger, S. (1994). An overview of nine decades of group psychotherapy. Hospital and Community Psychiatry, 45, 217-225.

Schopler, J.H. \& Galinsk, M.J. (1993). Support groups as opens systems: A model for practice and research. Health \& Social Work, 18, 195-207.

Vinogradov, S. \& Yalom, I. D. (1992). Manual de psicoterapia de grupo. (D. Batista, Trad.). Porto Alegre: Artes Médicas.

World Health Organization (1993) Classificação dos transtornos mentais e de comportamento da CID-10. Porto Alegre: Artes Médicas.

Zimerman, D. E. (1997). Classificação geral dos grupos. Em D.E. Zimerman
\& L.C.Osório (Orgs.), Como trabalhamos com grupos (Cap.7, pp. 75-81). Porto Alegre: Artes Médicas.

Sobre as autoras:

Carla Guanaes é professora da Universidade de São Paulo em Ribeirão Preto. Marisa Japur é professora da Universidade de São Paulo, Ribeirão Preto.

Recebido em 28/11/2000

Revisado em 27/12/2000

Aceito em 6/02/2001 